Research Article

\title{
Impact Properties of Recycled Aggregate Concrete with Nanosilica Modification
}

\author{
Xingguo Wang $\mathbb{D}^{1,2}$ Fei Cheng, ${ }^{1}$ Yixin Wang $\mathbb{D}^{1},{ }^{1}$ Xianggang Zhang, ${ }^{1,2}$ and Haicheng Niu ${ }^{1,2}$ \\ ${ }^{1}$ School of Civil Engineering, Henan Polytechnic University, Jiaozuo 454003, Henan, China \\ ${ }^{2}$ Henan Province Engineering Laboratory for Eco-architecture and the Built Environment, Jiaozuo 454003, Henan, China
}

Correspondence should be addressed to Xingguo Wang; 40772006@qq.com and Yixin Wang; wyx@hpu.edu.cn

Received 5 March 2020; Revised 20 June 2020; Accepted 17 August 2020; Published 2 September 2020

Academic Editor: Xuemei Liu

Copyright $(2020$ Xingguo Wang et al. This is an open access article distributed under the Creative Commons Attribution License, which permits unrestricted use, distribution, and reproduction in any medium, provided the original work is properly cited.

The optimal soaking time and nanosilica concentration were chosen by the physical properties of the nanosilica-modified recycled aggregate. Recycled aggregate concrete (RAC) and nanosilica recycled aggregate concrete (SRAC) were fabricated by using ordinary recycled aggregate and nanosilica-modified recycled aggregate. Based on the comparative experimental study of basic mechanical properties, the effects of nanosilica recycled aggregate(SRA) modification and recycled aggregate(RA) replacement percentage on the basic mechanical properties of recycled concrete were analyzed. Finally, the split-Hopkinson pressure bar (SHPB) was used to conduct comparative experimental research on the impact resistance of recycled aggregate concrete and nanosilica-modified recycled aggregate concrete. The effects of nanosilica recycled aggregate modification and aggregate replacement percentage on failure morphology, dynamic peak stress, dynamic increase factor (DIF), dynamic peak strain were analyzed.

\section{Introduction}

With the acceleration of China urbanization process, natural sand and gravel, as important building materials, have been rapidly increasing in consumption. At the same time, a large amount of building waste has been randomly stacked and buried, which has seriously polluted the environment [1]. By pulverizing the construction waste, obtaining recycled aggregate (RA) and producing recycled aggregate concrete (RAC) can not only protect the environment but also reduce the consumption of natural sand and stone resources in the construction industry.

At present, the research results show that the mechanical properties of recycled concrete are weaker than normal concrete due to the high water absorption and high porosity of the recycled aggregate [1-3]. Defects in the mechanical properties of RA concrete have limited its large-scale application in construction sites. After the RA is soaked through acid solution, its mechanical properties will be improved [4-6]. The test results show that the compressive strength of RA concrete after soaking through $\mathrm{HCL}, \mathrm{HNO}_{3}$, and $\mathrm{H}_{2} \mathrm{SO}_{4}$ solutions has increased by more than $18 \%$.
Adding nano- $\mathrm{SiO}_{2}$ particle in the production of $\mathrm{RA}$ will also affect the mechanical properties of recycled concrete. The test results show that the compressive strength of RA concrete increased by $22 \%$ when the mixing amount of the nano- $\mathrm{SiO}_{2}$ particle is 3\% [7]. Ying et al.'s tests show that the incorporation of nanomaterials is not only beneficial for improving the mechanical properties of recycled concrete but also for improving the durability of recycled concrete [8]. Xiao et al. [9] carried out experimental tests on the dynamic mechanical properties of recycled concrete using SHPB test equipment under different conditions of replacement percentage $(0 \%-100 \%)$ and strain rate $\left(36 \mathrm{~s}^{-1}-111 \mathrm{~s}^{-1}\right)$ of RA. The results show that the dynamic peak stress and peak strain of recycled concrete increase with strain rate and show obvious strain rate sensitivity; as the replacement percentage increases, the dynamic peak stress of recycled concrete decreases; however, the dynamic peak strain increases. Li et al. [10] carried out experimental tests on the dynamic mechanical properties of recycled aggregate concrete (RAC) and carbonized RAC under different strain rate conditions. The results show that the sensitivity of the dynamic peak stress 
and elastic modulus of the RAC is higher than that of the carbonized RAC.

In recent years, the development of nanomaterials has brought new development ideas to the field of civil engineering. Existing results show that nano- $\mathrm{SiO}_{2}$ and nano$\mathrm{CaCO}_{3}$ have filling effect and nucleation effect. Nano-SiO also has volcanic ash activity, so nano- $\mathrm{SiO}_{2}$ and nano$\mathrm{CaCO}_{3}$ can improve the microstructure of cement mortar and concrete, strengthening the interface area, increasing their strength, and improving their durability, and the optimal contents of nano- $\mathrm{SiO}_{2}$ and nano- $\mathrm{CaCO}_{3}$ particles are around $1.0 \%$ and $3.0 \%$, corresponding to the highest measured mechanical strengths of the UHPC matrix $[11,12]$. Geopolymer concrete-incorporated cold-bonded fly ash aggregate, nanosilica, and steel fiber can be produced with compressive strength as high as $28.23 \mathrm{MPa}$ and 36.62 $\mathrm{MPa}$ at 28 and 90 days, respectively. Moreover, 2\% nanosilica and $1 \%$ steel fiber volume fraction were the most significant parameters to improve the transport properties [13].

Full replacement of natural coarse aggregates with recycled ones has remarkable effect on compressive strength and interfacial transition zone (ITZ) characteristics of concrete. Compressive strength, tensile strength, and $\mathrm{mi}-$ crostructure of concrete mixes are enhanced due to the incorporation of nanosilica [7, 14]. Moreover, RAC with the addition of $3 \%$ nano- $\mathrm{SiO}_{2}$ particles has similar mechanical characteristics compared to natural aggregate concrete (NAC) [15]. The beneficial effects of the nanosilica slurry on RAC's mechanical properties were depicted [16]. The nanosilica slurry enhanced the new interface transition zone (ITZ) between the old and new mortars in RAC and surfacestrengthened the old mortar through nanoindentation tests [16].

Hou et al. and Li et al. $[17,18]$ carried out experimental tests on the dynamic mechanical properties of recycled concrete at different impact speeds $(7.7 \mathrm{~m} / \mathrm{s}-11.6 \mathrm{~m} / \mathrm{s})$ using $\mathrm{SHPB}$ test equipment under different nano- $\mathrm{SiO}_{2}$ and nano$\mathrm{CaCO}_{3}$ particle content conditions. The results show that nanomaterials can increase the dynamic peak stress of recycled concrete, and nano- $\mathrm{SiO}_{2}$ has a better enhancing effect.

The authors would like to use nanosilica solution to modify RA and choose the optimal soaking time and nanosilica solution concentration by the comparative properties of RA. Moreover, impact properties of nanosilicamodified RA concrete (SRAC) would be carried out by SHPB test with different RA replacement percentages and impact pressure strengths (strain rate).

\section{Nanosilica-Modified Recycled Aggregate}

2.1. Materials. Recycled aggregates were made from waste concrete beams and tested samples in the laboratory. The size ranged from $4.75 \mathrm{~mm}$ to $19 \mathrm{~mm}$ for RAC and nanosilicamodified recycled aggregate concrete (SRAC). Nanosilica sol solution was obtained by adding water in the sol, in which parameters are given in Table 1 .
TABle 1: Parameters of nanosilica sol solution.

\begin{tabular}{lc}
\hline Item & Tested value \\
\hline $\mathrm{SiO}_{2}$ content $\left(25^{\circ} \mathrm{C}\right)$ & $30 \%$ \\
$\mathrm{Na}_{2} \mathrm{O}$ content $\left(25^{\circ} \mathrm{C}\right)$ & $0.28 \%$ \\
$\mathrm{pH}$ value $\left(25^{\circ} \mathrm{C}\right)$ & 9.7 \\
$\mathrm{Viscosity}\left(25^{\circ} \mathrm{C}\right)$ & $5.0 \mathrm{cp} \cdot \mathrm{Pa} \cdot \mathrm{s}$ \\
\hline
\end{tabular}

2.2. Soaking Method. The RA was pretreated with different soaking concentrations (1\%,2\%, and 3\%) and soaking times ( $24 \mathrm{~h}, 48 \mathrm{~h}$, and $72 \mathrm{~h})$. The recycled aggregates were taken out and dried, and their apparent density, crush index, and water absorption were tested. The influence of soaking time and nanosilica solution concentration on their performance was analyzed to determine the optimal soaking time and concentration.

\subsection{Test Results and Analysis}

2.3.1. Test Results. According to the China Standard for Quality and Inspection Methods of Sand and Stone for Common Concrete (JGJ52-2006), the main physical properties of RA were tested, shown in Table 2.

2.3.2. Test Analysis. When the soaking time was $24 \mathrm{~h}, 48 \mathrm{~h}$, and $72 \mathrm{~h}$, with the increasing of the apparent density, the soaking concentration, crush index, and water absorption of the RA were significantly improved (Figure 1). When the soaking time was $48 \mathrm{~h}$, as the soaking concentration increased from $0 \%$ to $2 \%$, the apparent density of the RA increased by $1.6 \%$, and the crush index and water absorption of the RA decreased by $19.54 \%$ and $21.45 \%$, respectively. This is mainly due to nanosilica and the C-S-H gel, which is the product of the pozzolanic reaction between nanosilica and $\mathrm{Ca}(\mathrm{OH})_{2}$, which fills some of the pores and cracks in the recycled aggregate $[7,11,12,14,15]$. However, as the soaking concentration increased from $2 \%$ to $3 \%$, the apparent density of the RA only increased by $0.23 \%$, and the crush index and water absorption decreased by only $2.39 \%$ and $2.12 \%$. This is mainly due to the precipitation of some nanosilica on the surface of the RA. As the concentration of the nanosilica solution increased, this phenomenon became more and more obvious, preventing nanosilica from entering the RA and reducing the modification effect.

When the soaking concentration was $1 \%, 2 \%$, and $3 \%$, with the increase of the soaking time, the apparent density, crushing index, and water absorption of the RA were significantly improved. As the soaking time was increased from $48 \mathrm{~h}$ to $72 \mathrm{~h}$, the apparent density of the recycled aggregate increased only by $0.26 \%$, and the crushing index and water absorption decreased by $0.94 \%$ and $1.32 \%$. Because the content of $\mathrm{Ca}(\mathrm{OH})_{2}$ in the old mortar of RA was limited, the modification effect decreased as the soaking time increased.

The better the physical properties of the recycled coarse aggregate, the better the modification effect on the mechanical properties of the recycled coarse aggregate $[4,19,20]$. Therefore, according to the test results, the 
TABLe 2: Physical performance of the nanosilica-modified RA.

\begin{tabular}{lccccc}
\hline Mix & Soaking time $(\mathrm{h})$ & Concentration $(\%)$ & Apparent density $\left(\mathrm{kg} / \mathrm{m}^{3}\right)$ & Crush index $(\%)$ & Absorption $(\%)$ \\
\hline RA-0-0 & 0 & 0 & 2564 & 19.70 & 18.41 \\
RA-24-1 & & 1 & 2573 & 18.00 & 4.80 \\
RA-24-2 & $24 \mathrm{~h}$ & 2 & 2589 & 17.50 & 4.57 \\
RA-24-3 & & 3 & 2596 & 16.66 & 15.85 \\
RA-48-1 & & 1 & 2593 & 15.47 & 4.29 \\
RA-48-2 & $48 \mathrm{~h}$ & 2 & 2605 & 16.01 & 3.77 \\
RA-48-3 & & 3 & 2611 & 15.70 & 4.13 \\
RA-72-1 & & 1 & 2595 & 2612 & 3.72 \\
RA-72-2 & $72 \mathrm{~h}$ & 2 & 2616 & 15.30 & 3.57 \\
RA-72-3 & & 3 & & \\
\hline
\end{tabular}

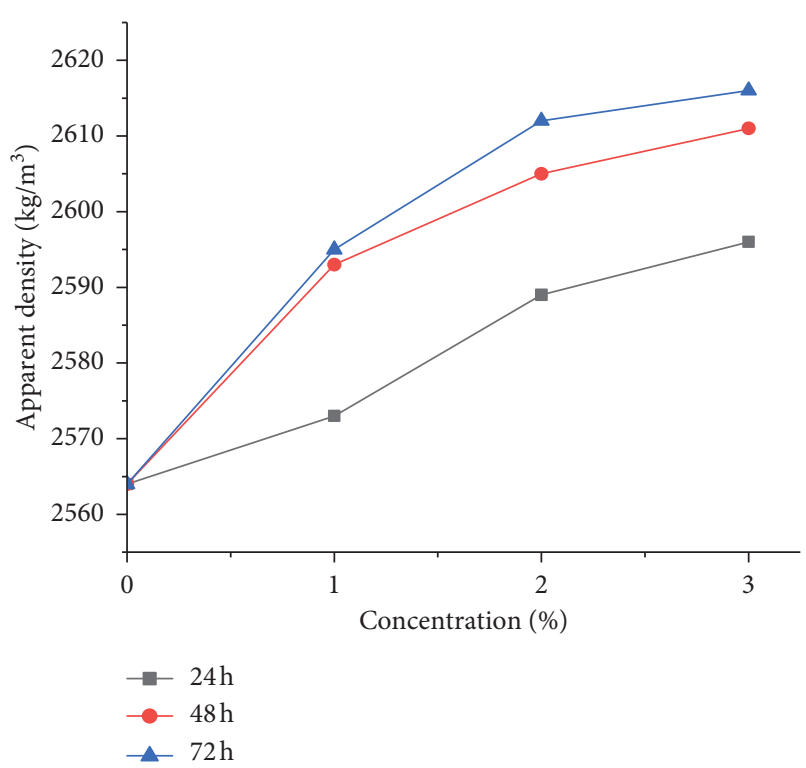

(a)

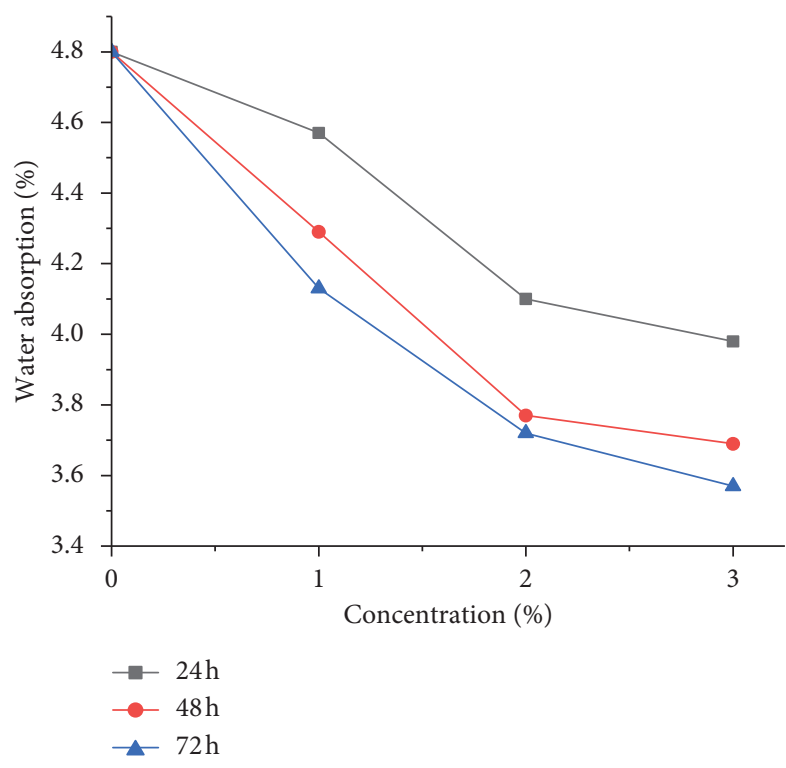

(b)

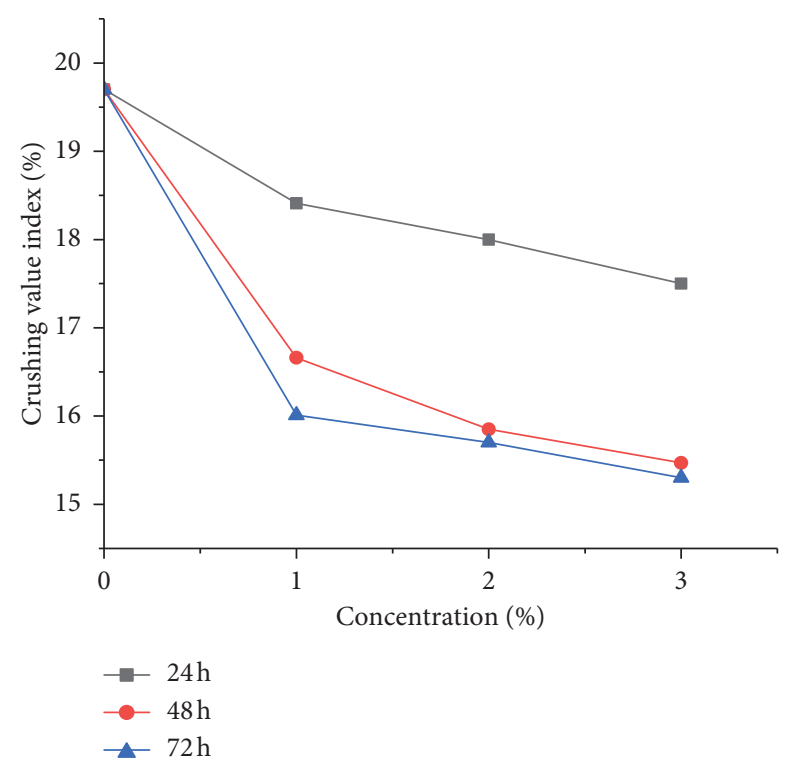

(c)

Figure 1: Physical properties of the RA after nanomodification. 
optimal soaking time and concentration would be $48 \mathrm{~h}$ and $2 \%$ in the following impact test.

\section{Impact Test Procedure}

3.1. Materials. The fine aggregate used local river sand. Natural coarse aggregate came from the local aggregate manufacturer. RA was obtained from crushed and sieved waste concrete in the laboratory. Nanosilica recycled aggregate (SRA) was obtained from the RA after soaking in the nanosilica solution. The main physical properties of the natural aggregate (NA), RA, and SRA are shown in Table 3. In order to obtain good working performance, superplasticizer would be used in the SRA modification.

3.2. Superplasticizer Amount. According to China Technical Specification for Concrete Admixtures (GBJ119-88), the suitable dosage of superplasticizer is $0.5 \%-1.0 \%$. Different superplasticizer admixtures, $0,0.5 \%, 0.7 \%$, and $1.0 \%(0$, $1.85 \mathrm{~kg} / \mathrm{m}^{3}, 2.6 \mathrm{~kg} / \mathrm{m}^{3}$, and $3.7 \mathrm{~kg} / \mathrm{m}^{3}$ ), were carried out to test the workability and compressive strength of RAC. The compressive strength test results are shown in Table 4 .

When the amount of superplasticizer is $3.7 \mathrm{~kg} / \mathrm{m}^{3}$, the slump is $140 \mathrm{~mm}$, but the workability of concrete is not good. When the amount of superplasticizer is $1.85 \mathrm{~kg} / \mathrm{m}^{3}$ and $2.6 \mathrm{~kg} / \mathrm{m}^{3}$, concrete has good workability and compressive strength, and the slump is $160 \mathrm{~mm}$ and $190 \mathrm{~mm}$, respectively. When the amount of superplasticizer is $1.85 \mathrm{~kg} / \mathrm{m}^{3}$, the work performance and workability are the best. So, the amount of superplasticizer in the following test is $1.85 \mathrm{~kg} / \mathrm{m}^{3}$.

3.3. Mixing Proportion of Concrete. In order to study the effect of RA replacement percentage $(R)(0 \%, 30 \%$, and $100 \%)$ and nanosilica-reinforced recycled aggregate on the mechanical properties of RAC, 5 groups of mixtures were designed. Due to the influence of the high water absorption of the RA on the working performance and mixing ratio of $\mathrm{RAC}$, the effective water/cement ratio was used to calculate the water consumption. The effective water-binder ratio was calculated according to the China Standard for Common Concrete Mix Proportion (JGJ552011) used in the mixing. Extra water for the RA could be obtained based on the water absorption and moisture content of the RA (Table 5).

3.4. Test Method for Impact Resistance. $\Phi 50 \mathrm{~mm} \times 25 \mathrm{~mm}$ cylindrical specimens were tested by variable cross-section split-Hopkinson pressure bar (SHPB) in the laboratory (Figure 2). Dynamic resistance strain gauge was used to amplify the strain signal. Dynamic test analyzer was used to display and store the amplified strain signal. Final test data could be obtained using the "two-wave method." $[9,18,21]$

\section{Impact Test Results}

4.1. Static Mechanical Results. Based on the China Standard for Test Methods of Mechanical Properties of Common Concrete (GB/T50081-2002), sizes of cubic specimens were
TABLE 3: Main physical properties of coarse aggregates.

\begin{tabular}{lccc}
\hline Type & $\begin{array}{c}\text { Apparent density }(\mathrm{kg} / \\
\left.\mathrm{m}^{3}\right)\end{array}$ & $\begin{array}{c}\text { Crush index } \\
(\%)\end{array}$ & $\begin{array}{c}\text { Absorption } \\
(\%)\end{array}$ \\
\hline NA & 2712 & 8.30 & 0.38 \\
RA & 2564 & 19.70 & 4.80 \\
SRA & 2605 & 15.85 & 3.77 \\
\hline
\end{tabular}

$100 \mathrm{~mm} \times 100 \mathrm{~mm} \times 100 \mathrm{~mm}, 100 \mathrm{~mm} \times 100 \mathrm{~mm} \times 300 \mathrm{~mm}$, and $100 \mathrm{~mm} \times 100 \mathrm{~mm} \times 400 \mathrm{~mm}$ for static property test (Table 6).

\subsection{Test Results of Impact Properties}

4.2.1. Damage Patterns. The impact typical failure patterns of specimens under different strengths are shown in Figure 3. Impact strength has a greater effect on the failure morphology.

As the impact strength increases, the degree of fragmentation of the specimen gradually deepens (Figure 3(a)). With increasing of the impact strength, the number of broken test pieces was larger, and the size was smaller. It shows that the strain rate has a greater effect on the failure shape of the test piece. When the impact strength is the same, the replacement percentage of the RA and the modified method of the RA have little effect on the morphology of failure (Figures 3(b) and 3(c)).

4.2.2. Dynamic Parameters and Stress-Strain Curves. Test parameters and results of impact specimens are shown in Table 7. Impact strength and strain curves are given in Figure 4 .

\section{Impact Result Analysis}

5.1. Mechanical Property Test Analysis. When the SRA replacement percentage increased from $0 \%$ to $100 \%$, its cubic compressive strength, axial compressive strength, and flexural strength decreased by $11.79 \%, 19.46 \%$, and $23.52 \%$, respectively. When the RA replacement ratio is $100 \%$, the cubic compressive strength and axial compressive strength of SRAC specimens are increased by $12.44 \%$ and $14.23 \%$, respectively, compared with the RAC specimens, but the flexural strength has little change. After the RA is modified by nanosilica solution, some nanomaterials would remain on the surface of the RA, and a large amount of $\mathrm{Ca}(\mathrm{OH})_{2}$ would be generated during the hydration process of the RA modification. The CSH gel, a product of the pozzolanic reaction between nanosilica and $\mathrm{Ca}(\mathrm{OH})_{2}$, also strengthened the ITZ of mortar of the RA [7, 14, 16, 22]. The physical properties of the RA were significantly improved by nanosilica modification. The lower water absorption rate reduces the porosity of recycled concrete, which improved the RA strength. Nanosilica remaining on the surface of the RA was partly mixed into the mortar during mixing of the concrete, and C-S-H gel played a role in strengthening the mortar. 
TABLE 4: Superplasticizer amount mixture.

\begin{tabular}{lcccccc}
\hline Number & Superplasticizer $\left(\mathrm{kg} / \mathrm{m}^{3}\right)$ & Water $\left(\mathrm{kg} / \mathrm{m}^{3}\right)$ & Cement $\left(\mathrm{kg} / \mathrm{m}^{3}\right)$ & Fine aggregate $\left(\mathrm{kg} / \mathrm{m}^{3}\right)$ & $\mathrm{RA}\left(\mathrm{kg} / \mathrm{m}^{3}\right)$ & Compressive strength $(\mathrm{MPa})$ \\
\hline 1 & 0 & 170 & 370 & 779.69 & 1060.8 & 42.27 \\
2 & 1.85 & 170 & 370 & 779.69 & 1060.8 & 41.30 \\
3 & 2.60 & 170 & 370 & 779.69 & 1060.8 & 41.57 \\
4 & 3.70 & 170 & 370 & 779.69 & 1060.8 & 36.43 \\
\hline
\end{tabular}

TABLE 5: Mixing proportion of different concretes.

\begin{tabular}{|c|c|c|c|c|c|c|c|c|c|c|}
\hline Mix & $\begin{array}{c}R \\
(\%)\end{array}$ & $w / c$ & $\begin{array}{c}\text { Superplasticizer }(\mathrm{kg} / \\
\left.\mathrm{m}^{3}\right)\end{array}$ & $\begin{array}{l}\text { Mix water } \\
\left(\mathrm{kg} / \mathrm{m}^{3}\right)\end{array}$ & $\begin{array}{c}\text { Cement } \\
\left.\mathrm{m}^{3}\right)\end{array}$ & $\begin{array}{l}\text { Sand }(\mathrm{kg} / \\
\left.\mathrm{m}^{3}\right)\end{array}$ & $\begin{array}{l}\text { NA }(\mathrm{kg} / \\
\left.\mathrm{m}^{3}\right)\end{array}$ & $\begin{array}{l}\mathrm{RA}(\mathrm{kg} / \\
\left.\mathrm{m}^{3}\right)\end{array}$ & $\begin{array}{c}\text { SRA }(\mathrm{kg} / \\
\left.\mathrm{m}^{3}\right)\end{array}$ & $\begin{array}{c}\text { Extra water } \\
\left(\mathrm{kg} / \mathrm{m}^{3}\right)\end{array}$ \\
\hline NAC & 0 & 0.46 & 1.85 & 170 & 370 & 779.69 & 1060.8 & 0 & 0 & \\
\hline RAC30 & 30 & 0.46 & 1.85 & 170 & 370 & 779.69 & 742.56 & 318.24 & 0 & 12.22 \\
\hline RAC100 & 100 & 0.46 & 1.85 & 170 & 370 & 779.69 & 0 & 1060.8 & 0 & 40.73 \\
\hline SRAC30 & 30 & 0.46 & 1.85 & 170 & 370 & 779.69 & 742.56 & 0 & 318.24 & 11.64 \\
\hline SRAC100 & 100 & 0.46 & 1.85 & 170 & 370 & 779.69 & 0 & 0 & 1060.8 & 38.08 \\
\hline
\end{tabular}

Note. NAC, RAC, and SRAC represent natural aggregate concrete, recycled aggregate concrete, and nanosilica-modified recycled aggregate concrete, respectively. $w / c$ represents the water/cement ratio.

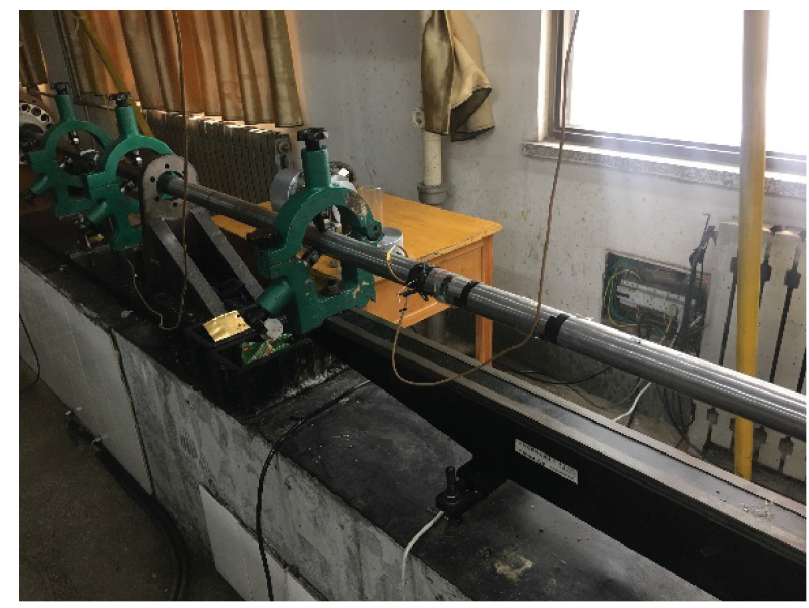

Figure 2: Schematic diagram of the Hopkinson rod test device.

TABLE 6: Static mechanical properties of different concretes.

\begin{tabular}{lccc}
\hline Specimen & Compressive strength of the cube $(\mathrm{MPa})$ & Axial compressive strength $(\mathrm{MPa})$ & Flexural strength $(\mathrm{MPa})$ \\
\hline NAC & 41.3 & 33.9 & 5.1 \\
RAC30 & 35.7 & 27.5 & 4.7 \\
RAC100 & 32.4 & 23.9 & 4.1 \\
SRAC30 & 38.6 & 30.1 & 4.8 \\
SRAC100 & 36.43 & 27.3 & 3.9 \\
\hline
\end{tabular}

\subsection{Impact Mechanical Performance}

5.2.1. Impact Peak Stress and Dynamic Amplification Factor. As the strain rate increases from $20 \mathrm{~s}^{-1}$ to $30 \mathrm{~s}^{-1}$ (Table 6), the dynamic peak stresses of NAC, RAC30, RAC100, SRAC30, and SRAC100 increase by $8.94 \%, 12.35 \%, 17.99 \%, 9.2 \%$, and $14.23 \%$, respectively. As the strain rate increased from $20 \mathrm{~s}^{-1}$ to $40 \mathrm{~s}^{-1}$, the dynamic peak stresses of NAC, RAC30, RAC100, SRAC30, and SRAC100 increased by $26.20 \%$, $26.34 \%, 29.04 \%, 31.18 \%$, and $23.01 \%$, respectively. It shows that when the strain rate increases, the dynamic peak stress had a linear increase trend, showing obvious strain rate sensitivity.

When the strain rate was $20 \mathrm{~s}^{-1}$, as the RA replacement percentage increased from $0 \%$ to $100 \%$, the dynamic peak stresses of RAC and SRAC decreased by $16.66 \%$ and $8.86 \%$, respectively. When the strain rate was $30 \mathrm{~s}^{-1}$, as the RA replacement percentage increased from $0 \%$ to $100 \%$, the dynamic peak stresses of RAC and SRAC decreased by $11.74 \%$ and $4.43 \%$, respectively. When the strain rate was $40 \mathrm{~s}^{-1}$, as the replacement percentage increased from $0 \%$ to $100 \%$, the dynamic peak stresses of RAC and SRAC decreased by $14.79 \%$ 


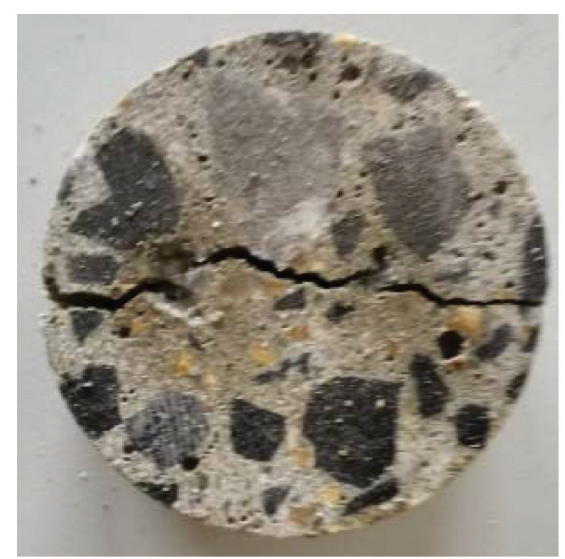

$0.2 \mathrm{MPa}$

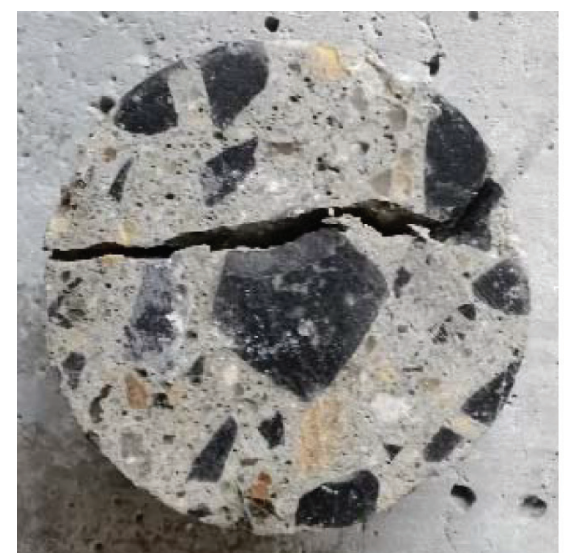

$0.2 \mathrm{MPa}$

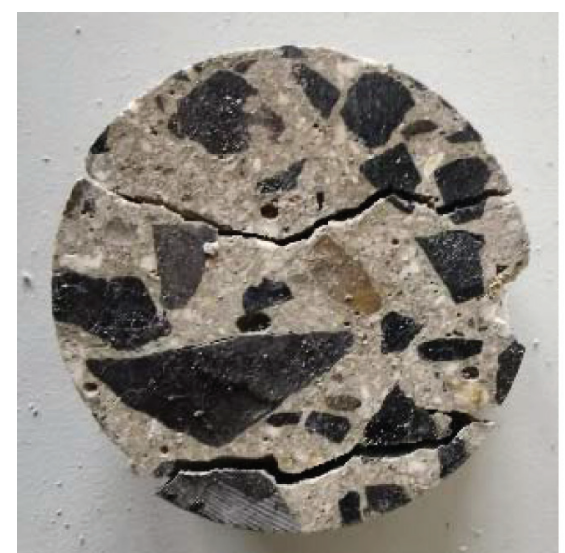

$0.2 \mathrm{MPa}$

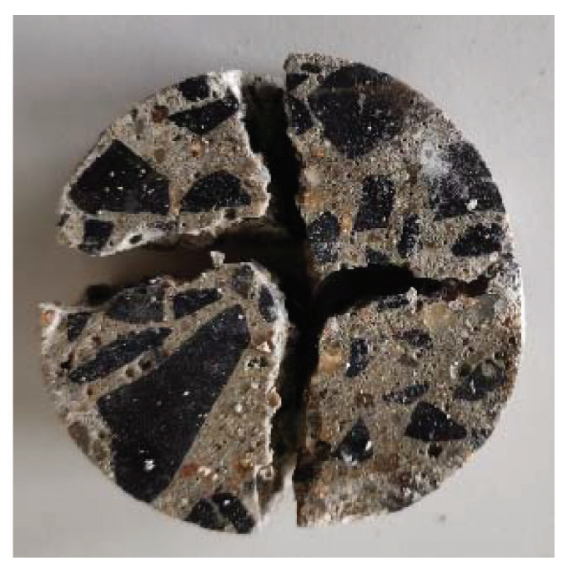

$0.25 \mathrm{MPa}$

(a)

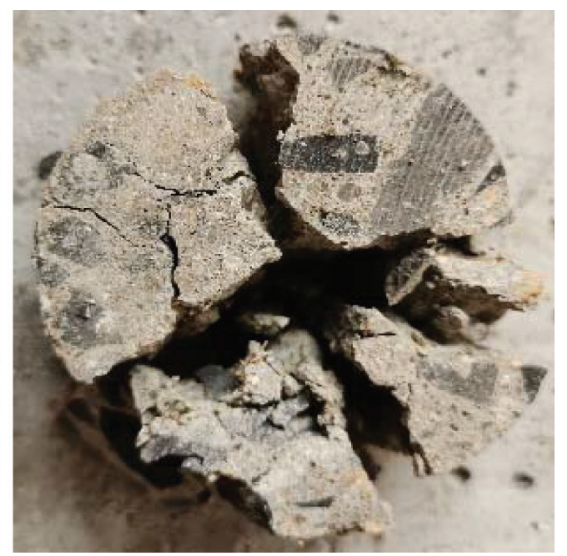

$0.25 \mathrm{MPa}$

(b)

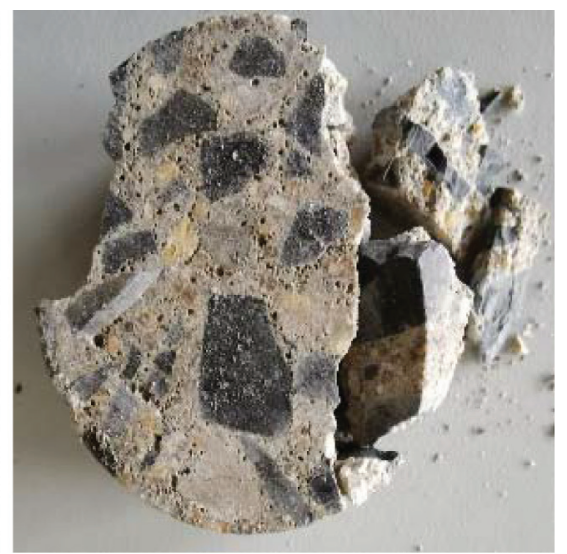

$0.25 \mathrm{MPa}$

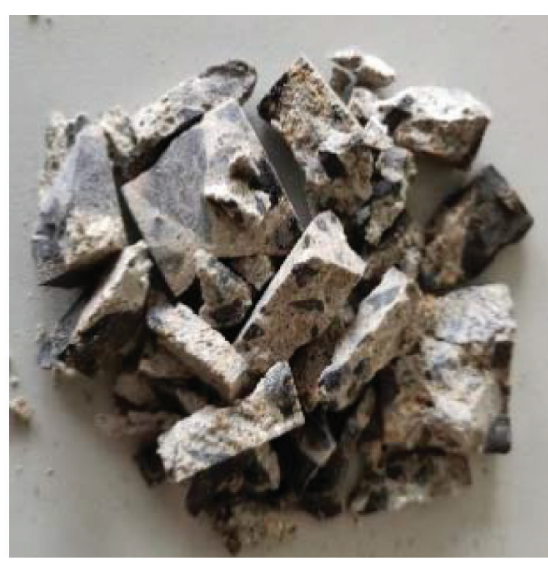

$0.3 \mathrm{MPa}$

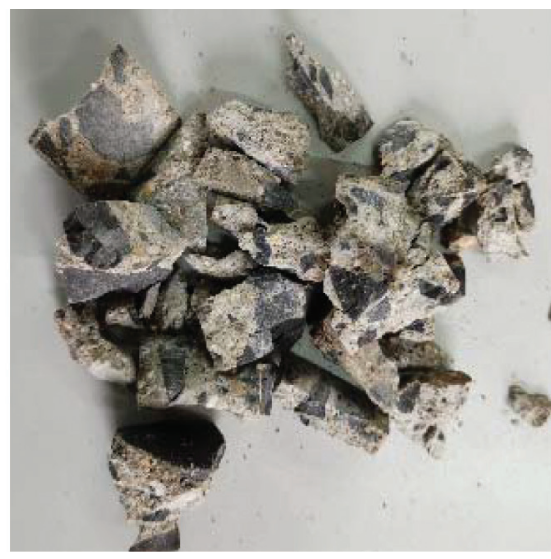

$0.3 \mathrm{MPa}$

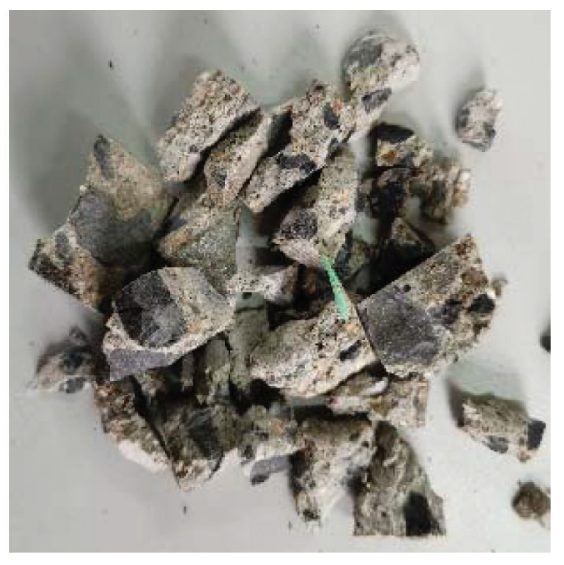

$0.3 \mathrm{MPa}$

(c)

FIGURE 3: Failure modes of the concrete specimen under different impact strengths: (a) NAC, (b) RAC100, and (c) SRAC100.

TABLE 7: SHPB test results of concrete specimens.

\begin{tabular}{|c|c|c|c|c|c|c|}
\hline Mixture & $\sigma_{0}(\mathrm{MPa})$ & Impact pressure $(\mathrm{MPa})$ & $\dot{\varepsilon}\left(\mathrm{s}^{-1}\right)$ & $\sigma_{\mathrm{d}}(\mathrm{MPa})$ & $\varepsilon_{\mathrm{p}}\left(10^{-3}\right)$ & DIF \\
\hline \multirow{4}{*}{ NAC } & \multirow{3}{*}{41.30} & 0.20 & 20.2 & 45.49 & 4.755 & 1.10 \\
\hline & & 0.25 & 32.6 & 49.56 & 4.981 & 1.20 \\
\hline & & 0.30 & 42.7 & 57.41 & 6.063 & 1.39 \\
\hline & \multirow{3}{*}{35.66} & 0.20 & 19.6 & 38.87 & 4.979 & 1.09 \\
\hline \multirow[t]{2}{*}{ RAC30 } & & 0.25 & 33.4 & 43.67 & 5.442 & 1.23 \\
\hline & & 0.30 & 43.6 & 49.11 & 5.848 & 1.38 \\
\hline
\end{tabular}


TABLE 7: Continued.

\begin{tabular}{|c|c|c|c|c|c|c|}
\hline Mixture & $\sigma_{0}(\mathrm{MPa})$ & Impact pressure $(\mathrm{MPa})$ & $\dot{\varepsilon}\left(\mathrm{s}^{-1}\right)$ & $\sigma_{\mathrm{d}}(\mathrm{MPa})$ & $\varepsilon_{\mathrm{p}}\left(10^{-3}\right)$ & DIF \\
\hline \multirow{3}{*}{ RAC100 } & \multirow{3}{*}{32.40} & 0.20 & 22.4 & 37.91 & 5.493 & 1.17 \\
\hline & & 0.25 & 31.3 & 43.74 & 5.974 & 1.35 \\
\hline & & 0.30 & 44.7 & 48.92 & 6.1 & 1.51 \\
\hline \multirow{3}{*}{ SRAC30 } & \multirow{3}{*}{38.60} & 0.20 & 20.4 & 42.07 & 5.176 & 1.09 \\
\hline & & 0.25 & 32.2 & 45.94 & 5.296 & 1.19 \\
\hline & & 0.30 & 41.9 & 55.19 & 6.185 & 1.44 \\
\hline \multirow{3}{*}{ SRAC100 } & \multirow{3}{*}{36.43} & 0.20 & 22.7 & 41.46 & 5.463 & 1.14 \\
\hline & & 0.25 & 31.9 & 47.36 & 5.854 & 1.30 \\
\hline & & 0.30 & 43.6 & 51.00 & 6.579 & 1.40 \\
\hline
\end{tabular}

Note. $\sigma_{0}$ represents the quasi-static compressive strength of the specimen; $\dot{\varepsilon}$ represents the average strain rate; $\sigma_{\mathrm{d}}$ represents the dynamic peak stress; $\varepsilon_{\mathrm{p}}$ represents the dynamic peak strain; and DIF represents the dynamic increase factor, DIF $=\sigma_{\mathrm{d}} / \sigma_{0}$.

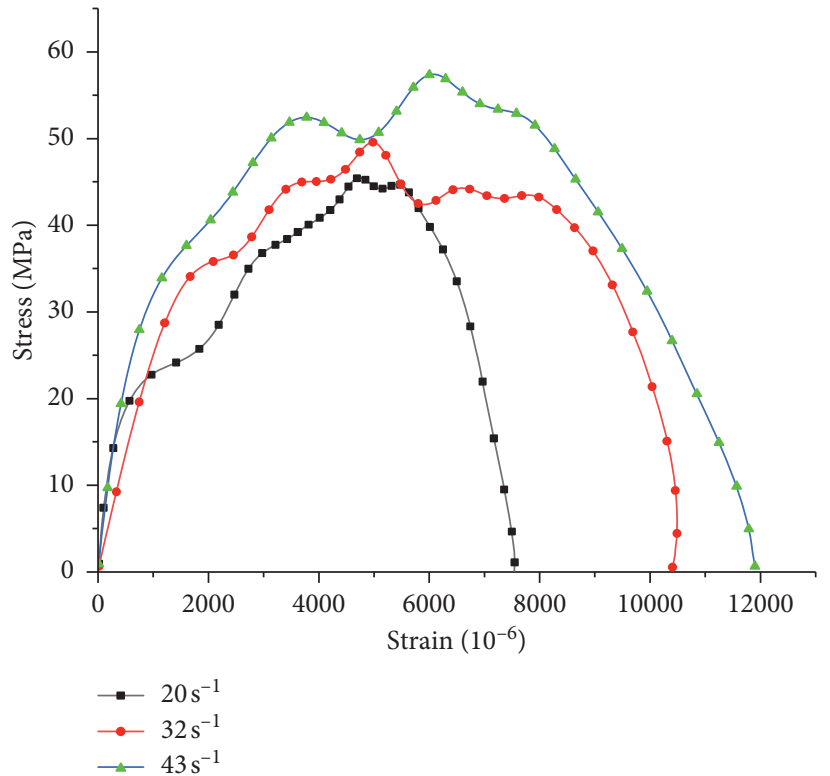

(a)

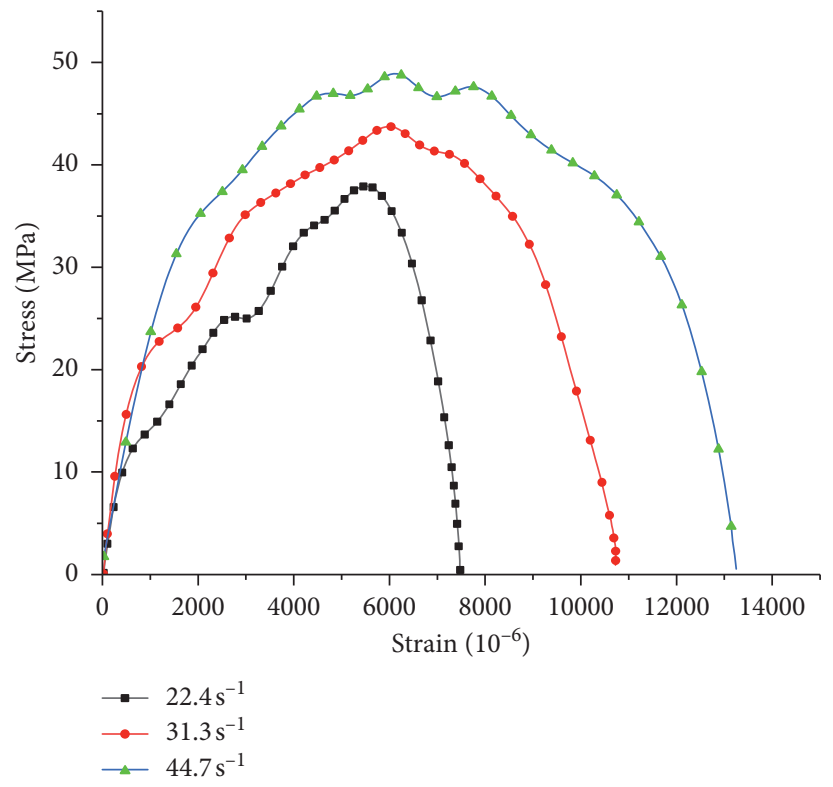

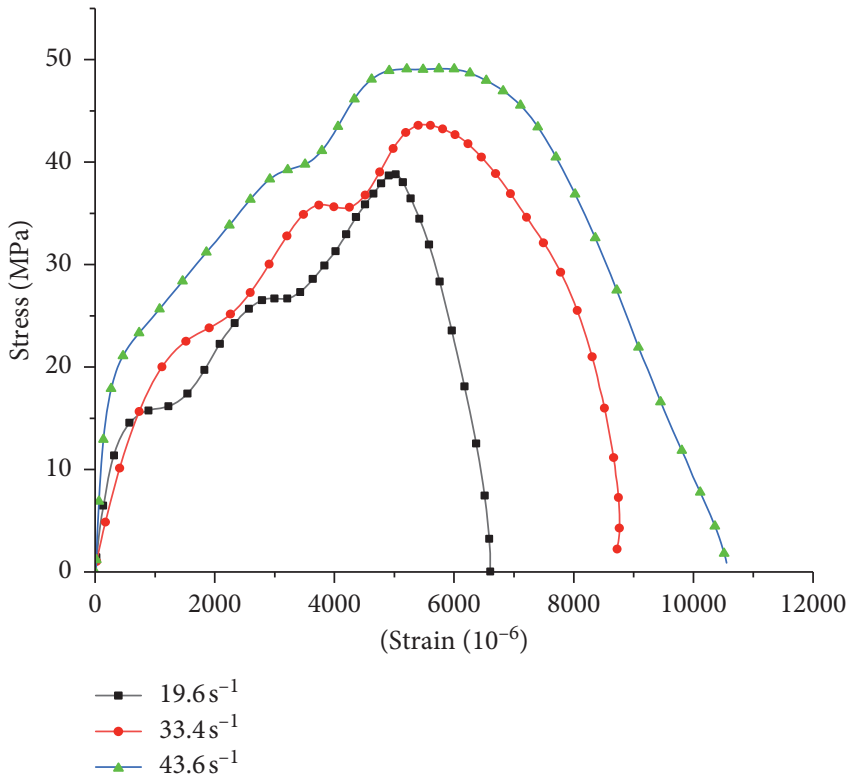

(b)

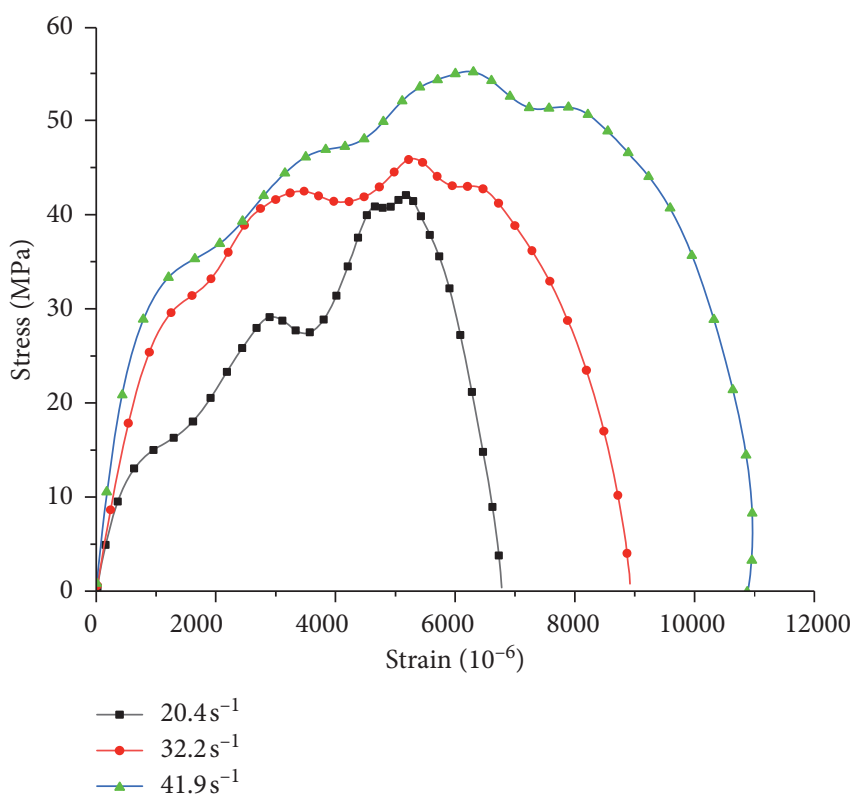

(c)

(d)

Figure 4: Continued. 


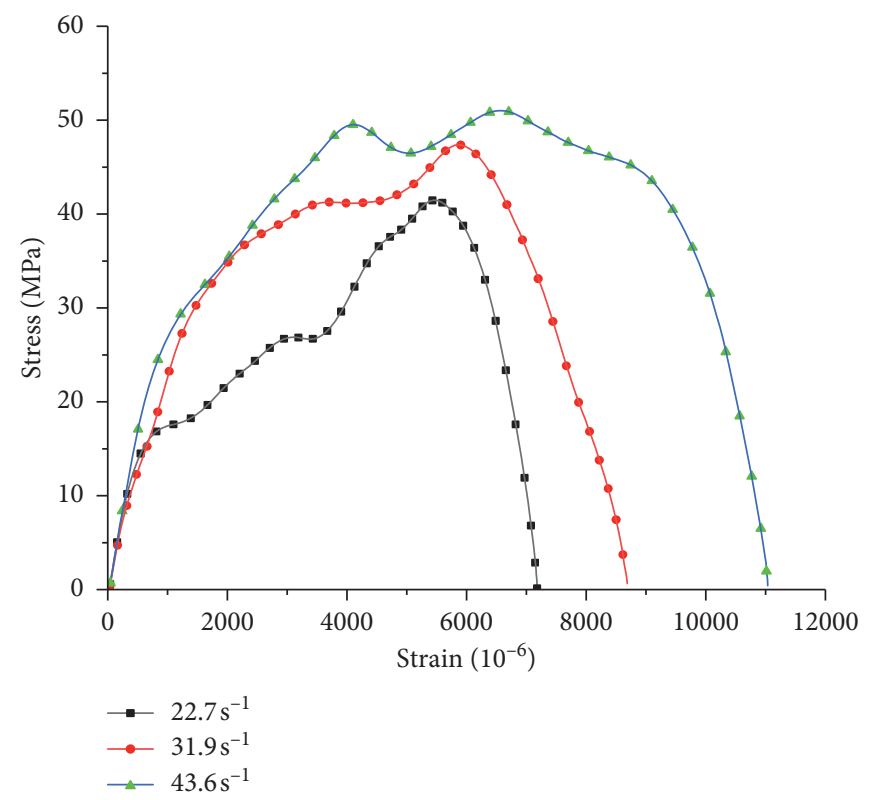

(e)

FIGURE 4: Impact stress-strain curves of different concretes: (a) NAC, (b) RAC30, (c) RAC100, (d) SRAC30, and (e) SRAC100.

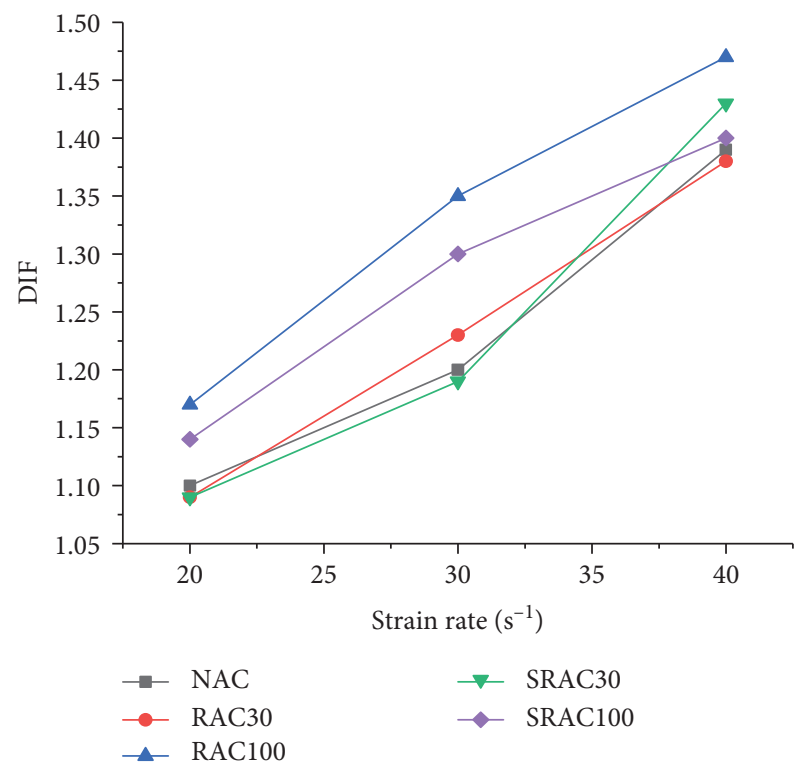

FigURE 5: DIF values of concrete specimens under different strain rates.

and $11.17 \%$, respectively. It shows that, as the RA replacement percentage increases, the dynamic peak stress shows a downward trend. When the replacement percentage is the same, the dynamic peak stress of SRAC is higher than that of RAC. Nanosilica modification had a significant improvement effect on the dynamic peak stress of recycled concrete.

For further discussing the strain rate sensitivity of SRAC, a dynamic increase factor (DIF) was introduced to reflect the dynamic peak stress increase. The DIF values of different concretes varied with the strain rate (Figure 5). It shows that the DIF value generally increases linearly with the increase of

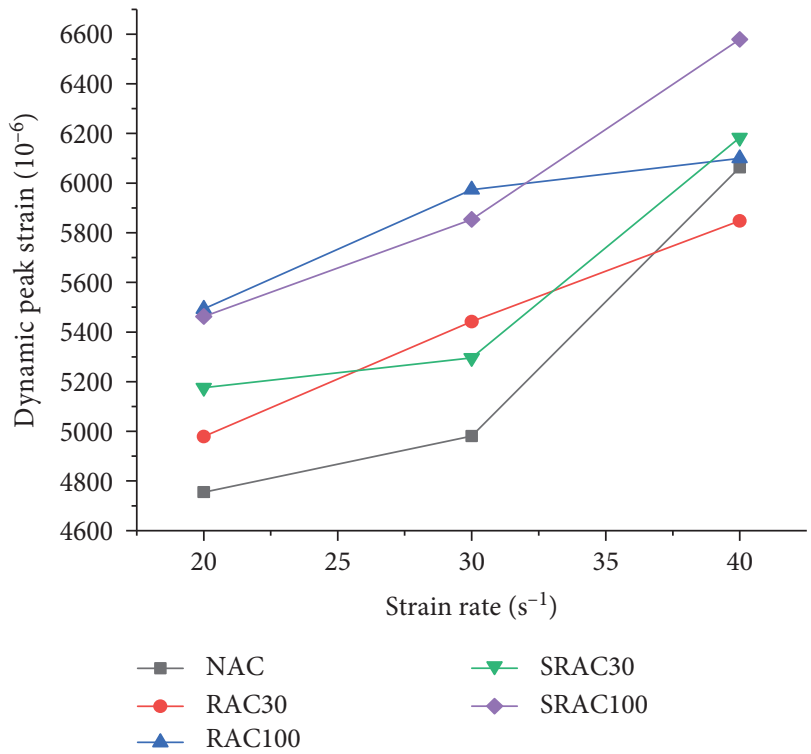

Figure 6: Peak strain of concrete specimens under different strain rates.

the strain rate. Under the same strain rate conditions, the DIF value of RAC100 was significantly higher than that of NAC and RAC30, and the DIF of SRAC100 was slightly lower than that of RAC100. Strain rate of RAC had more sensitivity than NAC. When the RA replacement percentage was $100 \%$, the addition of SRAC reduced the strain rate sensitivity of recycled concrete.

5.2.2. Dynamic Peak Strain. As the strain rate increases from $20 \mathrm{~s}^{-1}$ to $40 \mathrm{~s}^{-1}$, the dynamic peak strains of tested specimens 
increase approximately linearly, showing certain strain rate sensitivity (Figure 6). The dynamic peak strain of RAC100 is significantly higher than the other groups. When the strain is $20 \mathrm{~s}^{-1}, 30 \mathrm{~s}^{-1}$, the dynamic peak strain of SRAC100 is lower than that of RAC. However, when the strain rate is $40 \mathrm{~s}^{-1}$, the dynamic peak strain of SRAC100 is higher than RAC.

During the SHPB test, the impact time is very short, and a large number of cracks are too late to expand, which will inevitably lead to an increase in the peak strain. RA has low strength and loose porosity, which may have a greater impact on the dynamic peak strain.

\section{Conclusion}

(1) The combination of nanosilica solution concentration $2 \%$ and soaking time, $48 \mathrm{~h}$, has better modification effect on the mechanical properties of recycled aggregates. Its apparent density increased by $1.6 \%$, and crush index and water absorption decreased by $19.54 \%$ and $21.46 \%$.

(2) The nanosilica-modified recycled aggregate has a significant effect on improving the compressive strength and axial compressive strength of the recycled aggregate concrete cube, but it has little effect on the flexural strength.

(3) The dynamic peak stress of NAC, RAC, and SRAC showed a linear growth trend with the strain rate, and RAC100 had a better strain sensitivity. In addition, nanosilica-modified recycled aggregate reduced the strain rate sensitivity of RAC.

(4) The dynamic peak strains of NAC, RAC, and SRAC increased approximately linearly with the strain rate. When the strain rates were $20 \mathrm{~s}^{-1}$ and $30 \mathrm{~s}^{-1}$, the dynamic peak strain of RAC100 was the highest. However, when the strain was $40 \mathrm{~s}^{-1}$, SRAC100 had a better dynamic peak strain.

\section{Data Availability}

The data used to support the findings of this study are included within the article.

\section{Additional Points}

(i) Soaking time and concentration for the nanosilica-modified recycled aggregate were chosen. (ii) Nanosilica modification and recycled aggregate (RA) replacement percentage were analyzed for the property test of nanosilica recycled aggregate (SRA) concrete. (iii) Impact behaviors of SRA concrete were tested by using split-Hopkinson pressure bar (SHPB)

\section{Disclosure}

Xingguo Wang and Yixin Wang are the co-first authors.

\section{Conflicts of Interest}

The authors declare that there are no conflicts of interest regarding the publication of this article.

\section{Acknowledgments}

The authors would like to gratefully acknowledge Associate Professor Gong Jian, Henan Polytechnic University, for his assistance in the test process. The authors are also grateful to the Fundamental Research of Henan Nature Science Fund (182300410134, 182300410247, and 182102310877) and the Fundamental Research Funds for the Universities of Henan Province, Henan Polytechnic University (NSFRF200328 and NSFRF200320).

\section{References}

[1] J. Thomas, N. N. Thaickavil, and P. M. Wilson, "Strength and durability of concrete containing recycled concrete aggregates," Journal of Building Engineering, vol. 19, pp. 349-365, 2018.

[2] C. Zhou and Z. Chen, "Mechanical properties of recycled concrete made with different types of coarse aggregate," Construction and Building Materials, vol. 134, pp. 497-506, 2017.

[3] C. Wang, J. Xiao, and Z. Sun, "Influence of strain rate effect on mechanical behavior of recycled aggregate concrete," Journal of Tongji University (Natural Science), vol. 44, no. 8, pp. 1173-1181, 2016.

[4] P. Saravanakumar, K. Abhiram, and B. Manoj, "Properties of treated recycled aggregates and its influence on concrete strength characteristics," Construction and Building Materials, vol. 111, pp. 611-617, 2016.

[5] J. Wang, O. Geng, and F. Li, "Experiment on effect of several measures by modifying recycled coarse aggregate on improving compressive strength of concrete," Journal of Architecture and Civil Engineering, vol. 33, no. 2, pp. 91-97, 2016, in Chinese.

[6] X. Zhang, G. Wang, Z. Fang, X. Liu, W. Xu, and S. Lai, "Effect of mixing amount of aggregate intensified by RPC on the strength of recycled concrete," Journal of Building Materials, vol. 18, no. 3, pp. 400-408, 2015.

[7] B. B. Mukharjee and S. V. Barai, "Influence of nano-silica on the properties of recycled aggregate concrete," Construction and Building Materials, vol. 55, no. 2, pp. 29-37, 2014.

[8] J. Ying, B. Zhou, and J. Xiao, "Pore structure and chloride diffusivity of recycled aggregate concrete with nano- $\mathrm{SiO}_{2}$, and nano-TiO ${ }_{2}$," Construction and Building Materials, vol. 150, pp. $49-55,2017$.

[9] J. Xiao, L. Li, L. Shen, and S. P. Chi, "Compressive behavior of recycled aggregate concrete under impact loading," Cement and Concrete Research, vol. 71, pp. 46-55, 2015.

[10] L. Li, S. P. Chi, J. Xiao, and D. Xuan, "Effect of carbonated recycled coarse aggregate on the dynamic compressive behavior of recycled aggregate concrete," Construction and Building Materials, vol. 151, pp. 52-62, 2017.

[11] N. M. Garca, L. E. Zapata, O. M. Surez, and M. Cabrera-Ríos, "Effect of fly ash and nanosilica on compressive strength of concrete at early age," Advances in Applied Ceramics, vol. 114, no. 2, pp. 99-106, 2015.

[12] W. G. Li, Z. Huang, F. Cao, Z. Sun, and S. P. Shah, "Effect on nano-silica and nano-limestone on flowability and mechanical properties of ultra-high-performance concrete matrix," Construction and Building Materials, vol. 95, no. 1, pp. 366374, 2015.

[13] J. Musdif and Ö. Mustafa, "Developing geopolymer concrete by using cold-bonded fly ash aggregate, nano-silica, and steel 
fiber," Construction and Building Materials, vol. 180, pp. 1222, 2018.

[14] P. Hosseini, A. Booshehrian, and A. Madari, "Developing concrete recycling strategies by utilization of $\mathrm{Nano}-\mathrm{SiO}_{2}$ particles," Waste \& Biomass Valorization, vol. 2, no. 3, pp. 347-355, 2011.

[15] B. B. Mukharjee and S. V. Barai, "Influence of incorporation of nano-silica and recycled aggregates on compressive strength and microstructure of concrete," Construction and Building Materials, vol. 71, no. 2, pp. 570-578, 2014.

[16] H. Zhang, Y. Zhao, T. Meng, and S. P. Shah, "The modification effects of a nano-silica slurry on microstructure, strength, and strain development of recycled aggregate concrete applied in an enlarged structural test," Construction and Building Materials, vol. 95, pp. 721-735, 2015.

[17] P. Hou, S. Kawashima, D. Kong, D. J. Corr, J. Qian, and S. P. Shah, "Modification effects of colloidal nanoSiO 2 on cement hydration and its gel property," Composites Part B: Engineering, vol. 45, no. 1, pp. 440-448, 2013.

[18] W. Li, Z. Luo, C. Long, C. Wu, W. H. Duan, and S. P. Shah, "Effects of nanoparticle on the dynamic behaviors of recycled aggregate concrete under impact loading," Materials \& Design, vol. 112, pp. 58-66, 2016.

[19] S. C. Kou and C. S. Poon, "Effect of quality of parent concrete on the mechanical properties of high performance recycled aggregate concrete," Journal of the Chinese Ceramic Society, vol. 40, no. 1, pp. 7-11, 2012.

[20] S. C. Kou and C. S. Poon, "Properties of concrete prepared with PVA-impregnated recycled concrete aggregates," Cement and Concrete Composites, vol. 32, no. 8, pp. 649-654, 2010.

[21] W. Li, Z. Luo, C. Long, and L. Huang, "Experimental study on the dynamical mechanical performance of nanomodified recycled aggregate concrete," Journal of Hunan University (Natural Science), vol. 44, no. 9, pp. 92-99, 2017, in Chinese.

[22] Y. Fan, H. Niu, and X. Zhang, "Experimental study on nanomodified recycled aggregate concrete," Concrete, vol. 7, pp. 92-99, 2017, in Chinese. 